\title{
Caracterização histoquímica no diagnóstico da babesiose bovina por Babesia bovis ${ }^{1}$
}

\author{
Taiara M. Silva², Walter V.C. Areco², Tatiane C. Faccin², Stella M.P. Melo ${ }^{3}$, \\ Rafael A. Fighera ${ }^{4}$ e Glaucia D. Kommers ${ }^{4 *}$
}

\begin{abstract}
Silva T.M., Areco W.V.C., Faccin T.C., Melo S.M.P., Fighera R.A. \& Kommers G.D. 2018. [Histochemical characterization in the diagnosis of bovine babesiosis by Babesia bovis.] Caracterização histoquímica no diagnóstico da babesiose bovina por Babesia bovis. Pesquisa Veterinária Brasileira 38(4):649-658. Laboratório de Patologia Veterinária, Departamento de Patologia, Universidade Federal de Santa Maria, Av. Roraima 1000, Camobi, Santa Maria, RS 97105-900, Brazil. E-mail: glaukommers@yahoo.com

Babesiosis is a hemolytic tick-borne disease caused by intraerythrocytic protozoal parasites of the genus Babesia. This is a disease of high incidence in the southern Brazil and responsible for considerable economic losses. Clinical-pathological diagnosis can be made by demonstrating the parasite by examining blood smears or fresh tissues. However, frequently, only formalin-fixed organs are sent to pathology laboratories, which makes it impossible to perform the smears. The main objective of this study was to find alternative histochemical techniques capable to improve the identification of intraerythrocytic Babesia bovis in histological sections. For this study, tissue samples from 50 bovine necropsy cases were retrospectively analyzed, which had been fixed in formalin and routinely processed for histopathology. The cases were divided into a control group, consisting of 12 cases of cerebral babesiosis with characteristic pink-cherry gray matter (group A), and 38 cases suggestive of cattle tick fever (group B), according to necropsy protocols. Histochemical techniques of Alcian Blue, Methylene Blue, Toluidine Blue, Giemsa, Gram (McCallum-Goodpasture method), Grocott, Periodic Acid of Schiff and Ziehl-Neelsen were tested. Among these, it was observed that the techniques of Methylene Blue and Toluidine Blue allowed to observe morphological and dye characteristics in a clearer way, aiding in the identification of B. bovis. In addition, several clinical-epidemiological and anatomopathological parameters of babesiosis caused by $B$. bovis were established.
\end{abstract}

INDEX TERMS: Histochemical diagnosis, babesiosis, Babesia bovis, Methylene Blue, Toluidine Blue, disease of cattle, cattle tick fever, parasitoses.

RESUMO.- A babesiose é uma doença hemolítica transmitida por carrapatos e causada por protozoários intraeritrocitários do gênero Babesia. Esta é uma doença de incidência elevada na Região Sul do Brasil e responsável por perdas econômicas

\footnotetext{
${ }^{1}$ Recebido em 25 de abril de 2017.

Aceito para publicação em 19 de junho de 2017.

Parte da Dissertação de Mestrado do primeiro autor.

${ }^{2}$ Programa de Pós-Graduação em Medicina Veterinária, área de concentração em Patologia e Patologia Clínica Veterinária, Centro de Ciências Rurais (CCR), Universidade Federal de Santa Maria (UFSM), Av. Roraima 1000, Camobi, Santa Maria, RS 97105-900, Brasil.

${ }^{3}$ Curso de Medicina Veterinária, Centro de Ciências Rurais (CCR), Universidade Federal de Santa Maria (UFSM), Av. Roraima 1000, Camobi, Santa Maria, RS 97105-900.

${ }^{4}$ Laboratório de Patologia Veterinária, Departamento de Patologia, Centro de Ciências daSaúde, Universidade Federal de Santa Maria (UFSM), Av. Roraima 1000, Camobi, Santa Maria, RS 97105-900.*Autor para correspondência: glaukommers@yahoo.com
}

consideráveis. O diagnóstico clínico-patológico pode ser feito através da demonstração do parasito pelo exame de esfregaços sanguíneos ou de tecidos frescos. Entretanto, com frequência, somente órgãos fixados em formol são remetidos para laboratórios de patologia, o que impossibilita a realização do esfregaço. 0 principal objetivo deste estudo foi encontrar técnicas histoquímicas alternativas e capazes de aprimorar a evidenciação de Babesia bovis intraeritrocitária em tecidos fixados em formol. Para este estudo, foram analisadas retrospectivamente amostras de tecidos de 50 casos de necropsias de bovinos, as quais haviam sido fixadas em formol e processadas rotineiramente para histopatologia. Os casos foram divididos em um grupo controle, constituído por 12 casos de babesiose cerebral com substância cinzenta encefálica róseo-cereja característica (grupo A), e 38 casos sugestivos de tristeza parasitária bovina (grupo B), conforme 
os protocolos de necropsias. Foram testadas as técnicas histoquímicas de Azul Alciano, Azul de Metileno, Azul de Toluidina, Giemsa, Gram (método de McCallum-Goodpasture), Grocott, Ácido Periódico de Schiff e Ziehl-Neelsen. Dentre estas, observou-se que as técnicas de Azul de Metileno e Azul de Toluidina permitiram observar características morfológicas e tintoriais de maneira mais nítida, auxiliando na identificação de $B$. bovis. Adicionalmente, foram estabelecidos vários parâmetros clínico-epidemiológicos e anatomopatológicos da babesiose por B. bovis.

TERMOS DE INDEXAÇÃO: Histoquímica, bovinos, babesiose, Babesia bovis, Azul de Metileno, Azul de Toluidina, doenças de bovinos, tristeza parasitária bovina, parasitoses.

\section{INTRODUÇÃO}

Babesiose é uma doença hemolítica transmitida por carrapatos (Rhipicephalus microplus) e causada por protozoários intraeritrocitários do gênero Babesia (De Vos \& Potgieter 1994, Barros et al. 2006, Farias 2007, Fighera \& Graça 2010). Este parasito causa a babesiose, doença que pertence ao complexo denominado tristeza parasitária bovina (TPB), no qual ainda está envolvido o agente etiológico Anaplasma spp. A TPB tem grande importância econômica no Brasil devido às perdas com mortes, prevenção e tratamento dos animais (Patarroyo et al. 1982, Kessler et al. 1983, De Vos \& Potgieter 1994, Almeida et al. 2006, Uilenberg 2006). No Brasil, há somente duas espécies responsáveis pela babesiose em bovinos, sendo elas $B$. bovis e B. bigemina. A primeira, uma babesia pequena, é a mais patogênica e responsável pelo desenvolvimento de sinais nervosos nos bovinos, denominada babesiose cerebral. Ambas as babesias desenvolvem uma doença hemolítica caracterizada por anemia, febre, icterícia e hemoglobinúria, entretanto, a babesiose por Babesia bigemina causa uma doença mais branda (Kessler et al. 1983, De Vos \& Potgieter 1994, Barros et al. 2006, Fighera \& Graça 2010).

Como os sinais clínicos de babesiose são muito semelhantes entre as duas espécies, quando não há sinais neurológicos, é muito comum que ambas sejam confundidas clinicamente (De Vos \& Potgieter 1994) e até mesmo com outras doenças (Costa et al. 2011), incluindo anaplasmose, na qual não se observa hemoglobinúria (Barros et al. 2006). Nas infecções por B. bovis, podem ocorrer sinais neurológicos o que pode constituir-se em um fator determinante para concluir o diagnóstico clínico (OIE 2010). Os sinais neurológicos são inespecíficos e, portanto, devem ser diferenciados de outras doenças que acometem o sistema nervoso central (SNC) de bovinos (Barros et al. 2006). Os sinais neurológicos, na babesiose cerebral, são resultado do sequestro de eritrócitos nos capilares do cérebro, conferindo a cor característica róseo-cereja, pois $B$. bovis induz a aderência dos eritrócitos uns aos outros e à parede vascular de capilares sanguíneos (Callow \& McGavin 1963, Rodrigues et al. 2005, Antoniassi et al. 2009, Fighera \& Graça 2010).

O diagnóstico clínico de babesiose pode ser feito a partir dos sinais clínicos aliados à observação de parasitos intraeritrocitários em esfregaços sanguíneos (Callow \& McGavin 1963, Patarroyo et al. 1982, Sanches et al. 2000, Fighera 2001, Rodrigues et al. 2005, Almeida et al. 2006, Costa et al. 2011). Já a demonstração do parasito em animais mortos pode ser feita pelo exame de esfregaços de sangue periférico (quando a morte for recente) e tecidos como encéfalo, rins, coração, baço e fígado (Callow \& McGavin 1963). Os esfregaços podem ser corados com Giemsa (Callow \& McGavin 1963, Patarroyo et al. 1982, Kessler et al. 1983, OIE 2010) ou panótico rápido (Rodrigues et al. 2005, Fighera \& Graça 2010). Entretanto, tal técnica só pode ser realizada em tecidos frescos. Porém, com frequência, os órgãos remetidos aos laboratórios de patologia estão fixados em formol.

Através do exame histopatológico há uma alta frequência de diagnósticos sugestivos de babesiose/TPB devido à dificuldade de se observar os organismos intraeritrocitários por meio da coloração de rotina (hematoxilina e eosina) e também pela escassez de informações sobre colorações especiais que os evidenciem. Além disso, a utilização da técnica de imunohistoquímica, que possibilitaria a identificação de antígenos espécie-específicos, não está disponível pela ausência de anticorpos comerciais, e a utilização da reação em cadeia de polimerase (PCR) poderia ser limitada, considerando-se que a positividade para um determinado agente do complexo TPB não significa que os animais estejam doentes, pois poderiam ser apenas portadores destes micro-organismos (Barros et al. 2006, Néo et al. 2016).

Sendo assim, o objetivo deste estudo foi encontrar técnicas histoquímicas alternativas e capazes de aprimorar a evidenciação de B. bovis intraeritrocitária em tecidos fixados e processados rotineiramente para histopatologia. Adicionalmente foram revisados os aspectos clínico-epidemiológicos e anatomopatológicos dos casos positivos para este agente.

\section{MATERIAL E MÉTODOS}

Para este estudo, foram revisados os protocolos de necropsias dos arquivos do Laboratório de Patologia Veterinária (LPV) da Universidade Federal de Santa Maria (UFSM), no período de 2010 a 2016, dos quais foram selecionados 12 casos de babesiose cerebral (grupo A) e 38 casos sugestivos de TPB (grupo B), totalizando 50 bovinos.

As necropsias foram realizadas pela equipe do LPV-UFSM ou por veterinários de campo. Foram coletadas dos protocolos informações como sexo, raça, idade, sinais clínicos, realização e tipo de tratamento, época do ano, lesões macroscópicas e microscópicas. Os 12 casos de babesiose cerebral foram selecionados pela alteração encefálica característica da doença, isto é, a coloração róseo-cereja da substância cinzenta e foram utilizados como controles positivos para esta infecção. Para os demais 38 casos deste estudo, os critérios de inclusão foram o histórico clínico e/ou lesões macroscópicas e/ou microscópicas descritas nos protocolos e sugestivas de babesiose/TPB, porém sem a coloração róseo-cereja encefálica.

Os espécimes haviam sido fixados em formol a $10 \%$ e processados rotineiramente para histopatologia. Os fragmentos de encéfalo, rim, fígado e baço foram selecionados para análise conforme indicação da literatura (Patarroyo et al. 1982, De Vos \& Potgieter 1994). Numa primeira etapa, os encéfalos incluídos em parafina, provenientes dos 12 casos de babesiose cerebral, foram cortados em seções de $3 \mu \mathrm{m}$ e corados pela hematoxilina e eosina (HE), para avaliação da presença de organismos intraeritrocitários; e pelas técnicas histoquímicas de Azul Alciano (AA), Azul de Metileno (AM), Azul de Toluidina (AT), Giemsa, Gram (método de McCallum-Goodpasture), Grocott, Ácido Periódico de Schiff (PAS) e Ziehl-Neelsen (ZN), na busca de protozoários intraeritrocitários. As técnicas de Giemsa, Grocott, PAS e ZN foram realizadas com base nos seus respectivos kits comerciais (EasyPath ${ }^{\circledR}$ ). Enquanto que as demais técnicas (AA e Gram) foram realizadas conforme Behmer et al. (1976) e Culling et al. (1985). As colorações 
AM e AT foram adaptadas de Behmer et al. (1976) e constituíram-se de desparafinização, desidratação, exposição ao corante por dois minutos e lavagem em água corrente por um minuto para AM e água destilada para AT, seguido de desidratação, clarificação e montagem.

Após todas estas colorações especiais serem realizadas nos casos do grupo A, avaliaram-se as lâminas, e apenas as técnicas que evidenciaram os protozoários intraeritrocitários de maneira satisfatória, foram selecionadas e aplicadas nos demais órgãos do grupo A e nos 38 casos suspeitos de babesiose/TPB do grupo $\mathrm{B}$, com a finalidade de detectar casos com infecção por Babesia bovis. A morfologia de B. bovis, observada nos casos do grupo A, incluiu os critérios descritos na literatura: estruturas pequenas, redondas ou piriformes, com dimensões entre 1,5 e 2,4 $\mu$ m (Gardiner et al. 1998). Foram considerados como diagnósticos diferenciais as infecções por B. bigemina (organismo grande com 2,5 a 4,5 $\mu \mathrm{m}$, arredondado, piriforme arranjado em ângulo agudo) e por Anaplasma marginale (um ponto escuro, bem corado medindo 0,1 a $0,8 \mu \mathrm{m}$ ). Ao finalizar esta etapa no grupo B, somente foram avaliados os aspectos clínico-epidemiológicos e anatomopatológicos dos casos positivos para B. bovis.

As seções histológicas foram analisadas pelas técnicas histoquímicas em duas magnificações (400x em todos os casos e 1000x sob imersão, em casos selecionados). A visualização dos micro-organismos foi classificada em positiva (+ quando os protozoários foram facilmente observados), fraca (+/- quando foram observados protozoários, porém com pouca nitidez) ou negativa (- quando não foram observados protozoários intraeritrocitários). As imagens dos parasitos intraeritrocitários foram obtidas através de um microscópio Olympus BX51, com câmera digital DP21, controlada pelo programa Olympus CellSens ${ }^{\circledR}$.

\section{RESULTADOS}

\section{Grupo A}

Alterações clínico-epidemiológicas. No grupo A (babesiose cerebral), os 12 bovinos morreram espontaneamente. Dentre eles, nove eram fêmeas e três eram machos. A idade variou de três semanas a sete anos, sendo que animais entre um e três anos foram os mais acometidos. Quanto à raça, três eram sem raça definida (SRD) e os nove animais restantes eram de raças de origem europeia. Os casos ocorreram principalmente no verão (5/12) e outono (4/12). 0 tratamento específico para TPB foi realizado em cinco casos. Dentre os fármacos mais utilizados estavam o diaceturato de diminazeno, dipropionato de imidocarb e oxitetraciclina.

Os principais sinais neurológicos descritos foram tremores (2/12), incoordenação motora (5/12), paralisia dos membros pélvicos (1/12), agressividade (1/12), desvio lateral do pescoço e andar em círculo (1/12), decúbito lateral (1/12), pressão da cabeça contra objetos e movimentos constantes da cabeça $(1 / 12)$. Outros sinais clínicos inespecíficos encontrados foram apatia $(3 / 12)$, anorexia $(3 / 12)$, febre $(3 / 12)$, sialorreia $(3 / 12)$, diarreia (2/12), debilidade (2/12), taquicardia, taquipneia e diminuição dos movimentos ruminatórios (1/12), afastamento do rebanho (1/12), prostração (1/12), fraqueza (1/12), icterícia (1/12) e mucosas pálidas (interpretado como anemia) (1/12).

Lesões macroscópicas. Nos 12 casos desse grupo, a lesão macroscópica encefálica (critério de inclusão) foi a coloração róseo-cereja da substância cinzenta (Fig.1 e 2). 0 rim foi remetido em sete casos (7/12) e em quatro (4/7) deles estava vermelho-escuro (Fig.3). 0 fígado foi remetido em nove casos (9/12) e estava alaranjado, castanho-amarelado ou escuro e com hepatomegalia (Fig.4 e 5). 0 baço foi enviado em oito casos (8/12), nos quais havia congestão, esplenomegalia e protrusão da polpa vermelha sobre a cápsula (Fig.6).

Lesões microscópicas. No encéfalo, havia congestão dos capilares sanguíneos da substância cinzenta em todos os casos (12/12) (Fig.7). A presença de Babesia bovis foi relatada em sete casos (7/12) através do esfregaço do tecido encefálico quando remetido não fixado. No rim, foi observada necrose tubular com regeneração ou associada a cilindros de hemoglobina (6/7), material hialino (proteináceo) nos espaços urinários (4/7), congestão de vasos sanguíneos (4/7) e focos de hemorragia na região medular (1/7). No fígado havia pigmento amarelo-ouro (bilestase) no interior de canalículos e/ou ductos biliares (7/9), necrose centrolobular e periportal, necrose aleatória de hepatócitos, leucocitostase, infiltrado inflamatório mononuclear associado à necrose aleatória de hepatócitos (2/9), deposição de pigmento granular

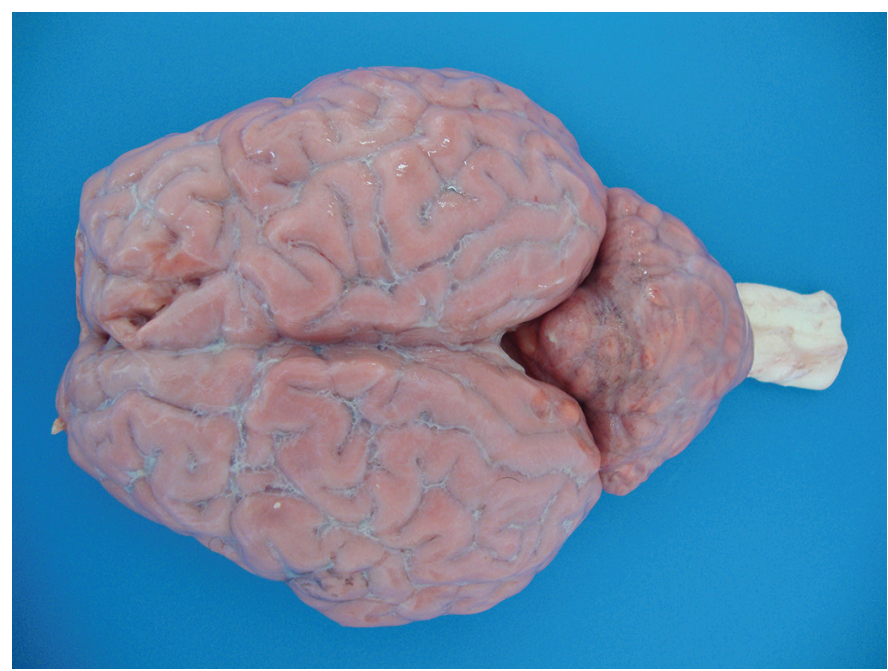

Fig.1. Encéfalo, substância cinzenta de coloração róseo-cereja. Note o contraste com a substância branca da medula espinhal.

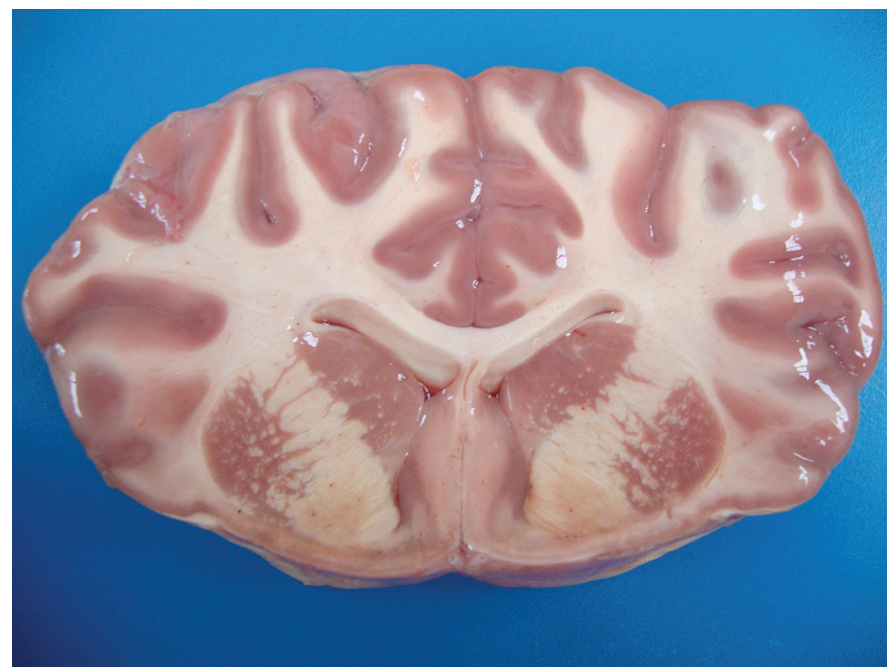

Fig.2. Encéfalo, lobo frontal na altura dos núcleos basais. Contraste da substância cinzenta de coloração róseo-cereja com a substância branca. 


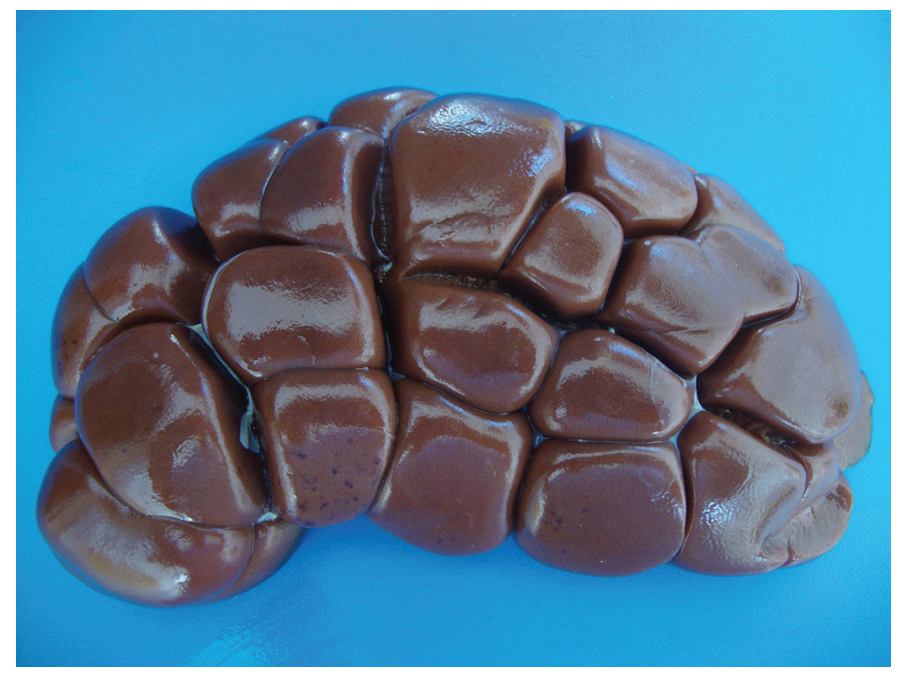

Fig.3. Rim, superfície capsular vermelho-escura característica de nefrose hemoglobinúrica.

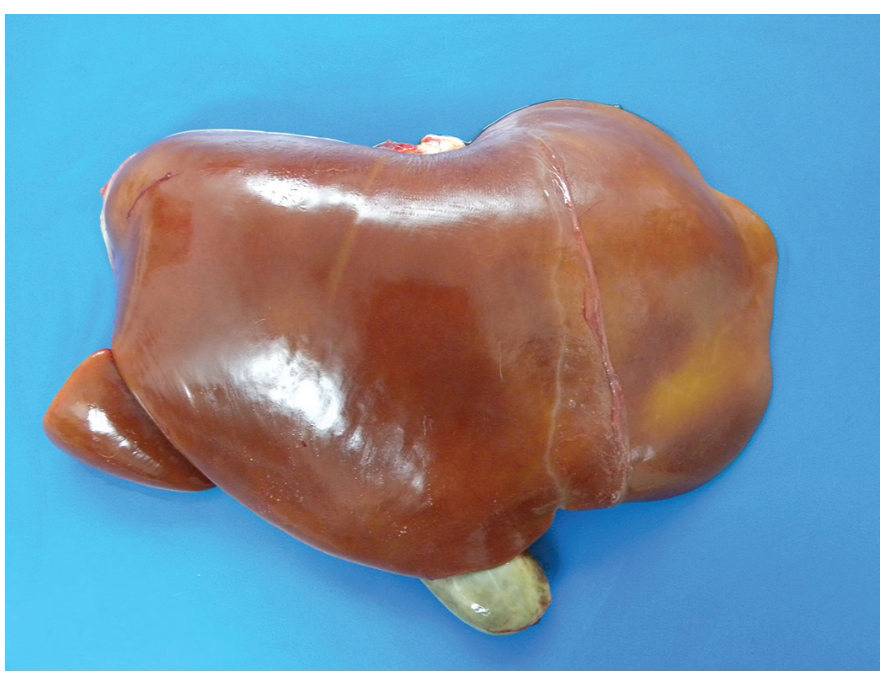

Fig.4. Fígado, aumentado de tamanho (hepatomegalia) e alaranjado.

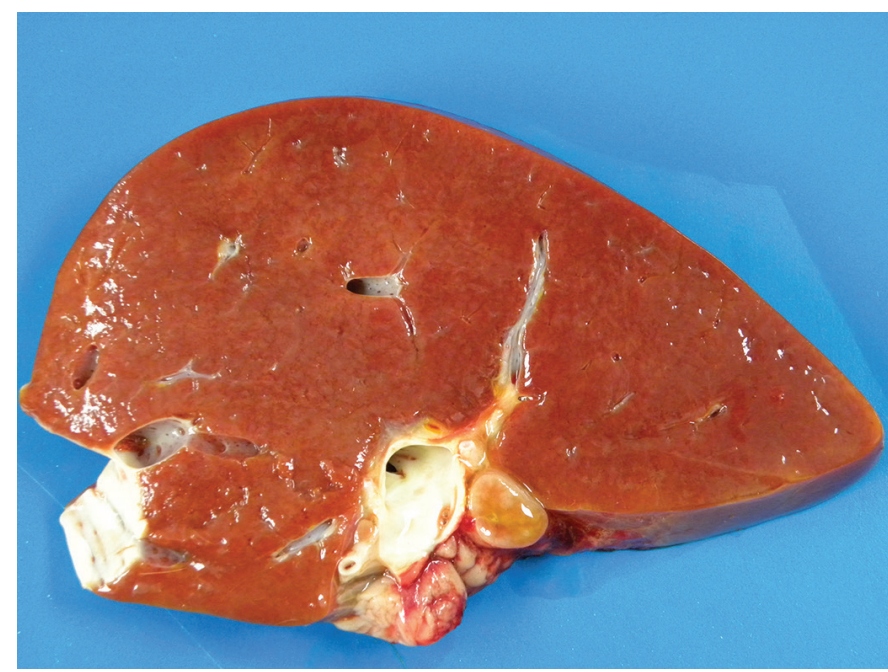

Fig.5. Fígado, superfície de corte, parênquima difusamente alaranjado devido à bilestase.

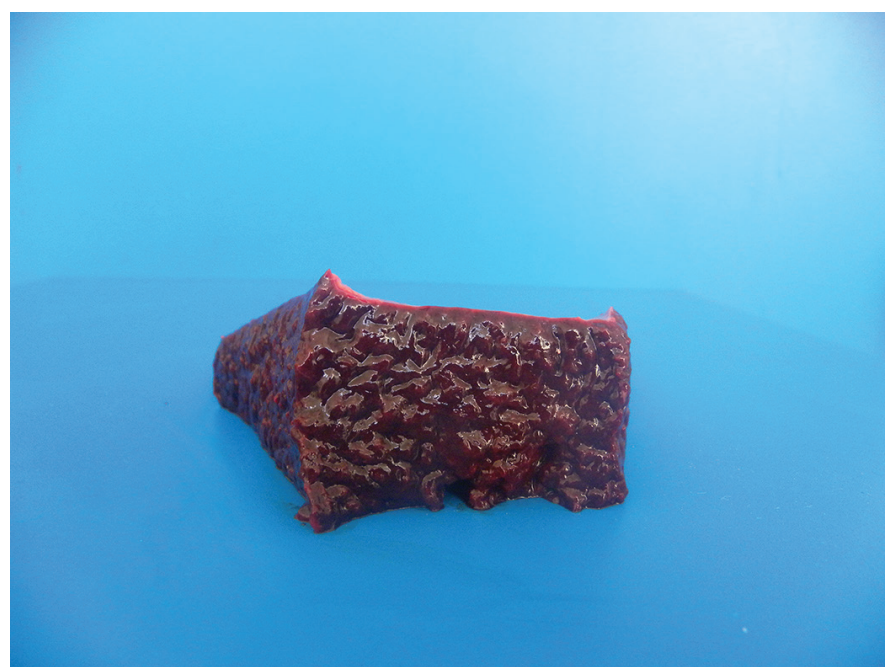

Fig.6. Baço, superfície de corte, o parênquima protrai sobre a cápsula indicando esplenomegalia.

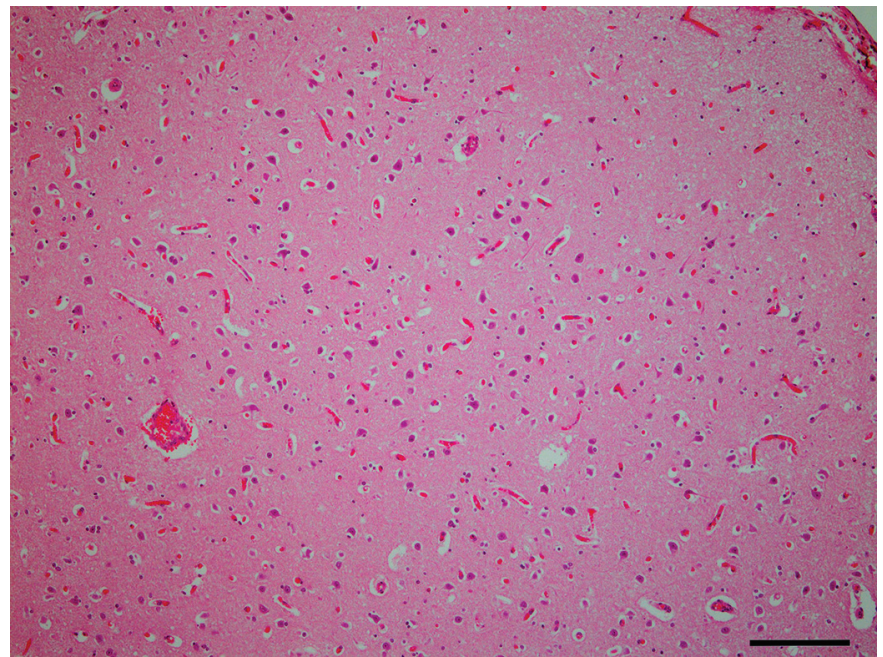

Fig.7. Encéfalo, congestão dos capilares do córtex telencefálico. HE, obj.10x.

marrom-dourado (hemossiderina) no interior das células de Kupffer (1/9), congestão do parênquima hepático (1/9), hematopoiese extramedular e eritrofagia (1/9). No baço, foram observadas congestão acentuada do parênquima esplênico (5/8), hematopoiese extramedular (2/8), eritrofagia e macrófagos contendo hemossiderina (2/9).

Aspectos histoquímicos. No Quadro 1 estão demonstrados os resultados das técnicas histoquímicas de HE, AM e AT. Em todos os casos do grupo A foram observados organismos intraeritrocitários no encéfalo através da coloração de rotina de HE, porém com nitidez limitada.

Dentre as colorações testadas neste estudo, a que resultou em melhor evidenciação dos protozoários foi o AM, pois corou os eritrócitos em azul-esverdeado mais claro e os organismos em azul-escuro, permitindo uma boa visualização e nitidez de sua morfologia. Este corante também faz parte da contracoloração da técnica de ZN, e desta forma os protozoários também 
Quadro 1. Propriedades histoquímicas da infecção por Babesia bovis nos bovinos do grupo A

\begin{tabular}{|c|c|c|c|c|c|c|c|c|c|c|c|c|}
\hline \multirow{2}{*}{ Caso no } & \multicolumn{3}{|c|}{ Encéfalo } & \multicolumn{3}{|c|}{ Rim } & \multicolumn{3}{|c|}{ Fígado } & \multicolumn{3}{|c|}{ Baço } \\
\hline & $\mathrm{HE}$ & $\mathrm{AM}$ & AT & $\mathrm{HE}$ & $\mathrm{AM}$ & AT & $\mathrm{HE}$ & $\mathrm{AM}$ & $\mathrm{AT}$ & $\mathrm{HE}$ & $\mathrm{AM}$ & AT \\
\hline 1 & $+/-$ & + & + & $+/-$ & + & + & - & + & + & $+/-*$ & + & + \\
\hline 2 & - & + & + & $+/-$ & $+/-^{*}$ & + & $+/-$ & $+/-*$ & + & • & $\bullet$ & $\bullet$ \\
\hline 4 & $+/-$ & + & + & $\bullet$ & $\bullet$ & $\bullet$ & - & + & + & - & + & + \\
\hline 5 & $+/-$ & + & + & $\bullet$ & $\bullet$ & $\bullet$ & $\bullet$ & $\bullet$ & $\bullet$ & • & • & $\bullet$ \\
\hline 8 & $+/-$ & + & + & $\bullet$ & $\bullet$ & $\bullet$ & $\bullet$ & • & • & • & $\bullet$ & $\bullet$ \\
\hline 9 & $+/-$ & + & + & - & - & - & - & - & - & - & - & + \\
\hline 10 & $+/-$ & + & + & $+/-$ & + & + & $+/-$ & + & + & $+*$ & + & + \\
\hline 11 & $+/-$ & + & + & $+/-$ & + & + & $+/-$ & + & + & $+/-$ & $+*$ & $+*$ \\
\hline 12 & $+/-$ & + & + & $+/-$ & + & + & $+/-$ & + & + & - & $+/-^{*}$ & $+/-^{*}$ \\
\hline
\end{tabular}

- Não remetido, ${ }^{*}$ casos em que foi necessário o uso do óleo de imersão na objetiva de 100x. A presença dos micro-organismos foi classificada em positiva (+ quando os protozoários foram facilmente observados), fraca (+/- quando foram observados protozoários, porém com pouca nitidez) ou negativa ( - quando não foram observados protozoários intraeritrocitários); HE = hematoxilina e eosina, $\mathrm{AM}=$ azul de metileno, $\mathrm{AT}=$ azul de toluidina.

puderam ser visualizados pelo ZN, porém não mostraram álcool-ácido resistência. A segunda técnica que se mostrou efetiva para a demonstração de $B$. bovis foi o AT, corando os eritrócitos em amarelo-esverdeado e os protozoários em azul-escuro. A coloração de Giemsa corou os parasitos em roxo-escuro, enquanto que as hemácias adquiriram um tom rosa-claro, permitindo sua visualização, porém com menor nitidez que o AM e o AT. O PAS evidenciou os protozoários por meio da sua contracoloração, hematoxilina de Carazzi, mas os organismos não foram PAS-positivos. As técnicas de Gram, AA e Grocott foram negativas.

No encéfalo, $B$. bovis foi observada principalmente em capilares da substância cinzenta (Fig.8-10). Porém, foi possível observar também em capilares da substância branca e em alguns vasos de maior calibre, onde os eritrócitos parasitados estavam aderidos à parede do vaso. No rim, os protozoários eram facilmente observados em capilares do interstício renal e dos glomérulos (Fig.11-13). No fígado, a visualização destes micro-organismos era mais clara em vasos dos espaços porta. Entretanto, quando havia uma alta parasitemia, também era possível observá-los em sinusoides e veias centrolobulares. Observou-se que nos materiais remetidos já fixados em formol, a visualização de $B$. bovis no baço foi prejudicada pela grande quantidade de pigmento de formol. Entretanto, nestas ocasiões, a observação de protozoários em capilares da cápsula esplênica auxiliou o diagnóstico. Nos casos em que havia grande quantidade de micro-organismos, estes organismos intraeritrocitários eram facilmente visualizados na polpa vermelha.

\section{Grupo B}

Através do tamanho e características morfológicas dos micro-organismos (que estão detalhados no item Aspectos histoquímicos), foi possível determinar a etiologia em 29 dos 38 bovinos suspeitos, perfazendo 76,32\% (29/38). Identificou-se B. bovis em 21 casos (21/29), B. bigemina em quatro casos (4/29) e Anaplasma marginale em quatro bovinos $(4 / 29)$. Nos nove casos negativos não foi possível identificar qualquer agente ou causa para os sinais clínicos e suspeita do

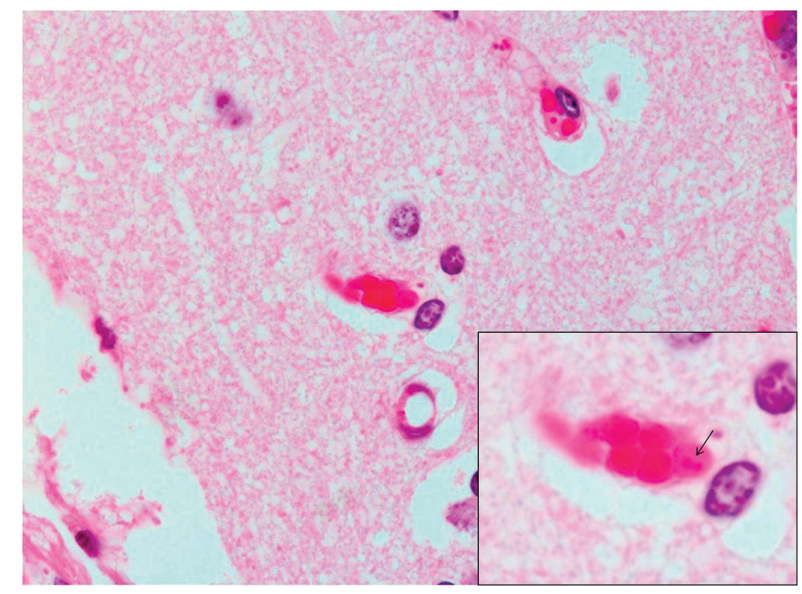

Fig.8. Encéfalo, congestão capilar. No detalhe observe o eritrócito parasitado por Babesia bovis (seta). HE, obj.100x.

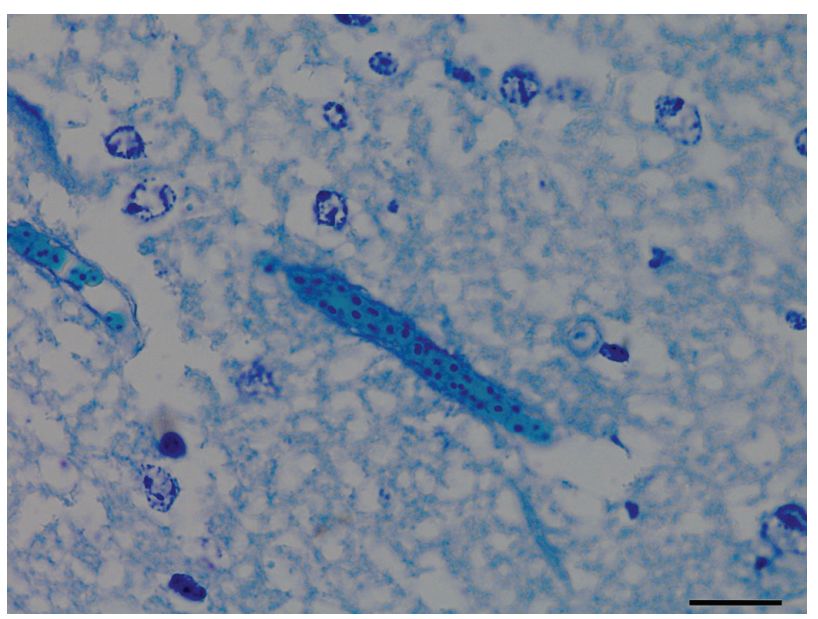

Fig.9. Encéfalo, congestão capilar com numerosos eritrócitos (azul-esverdeados) parasitados por Babesia bovis (azul-escuro). Azul de metileno, obj.100x. 


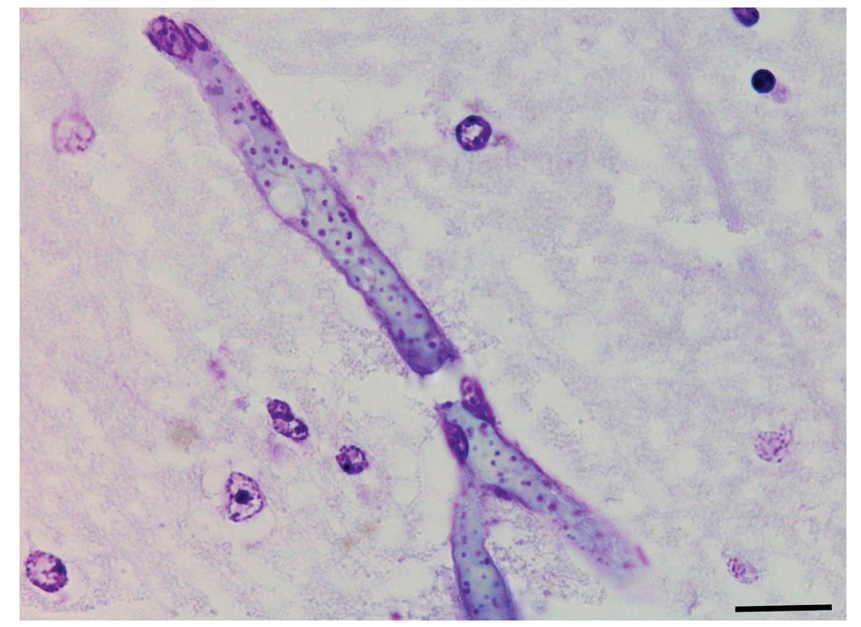

Fig.10. Encéfalo, congestão capilar com numerosos eritrócitos (amarelo-esverdeados) parasitados por Babesia bovis (azul-escuro). Azul de toluidina, obj.100x.

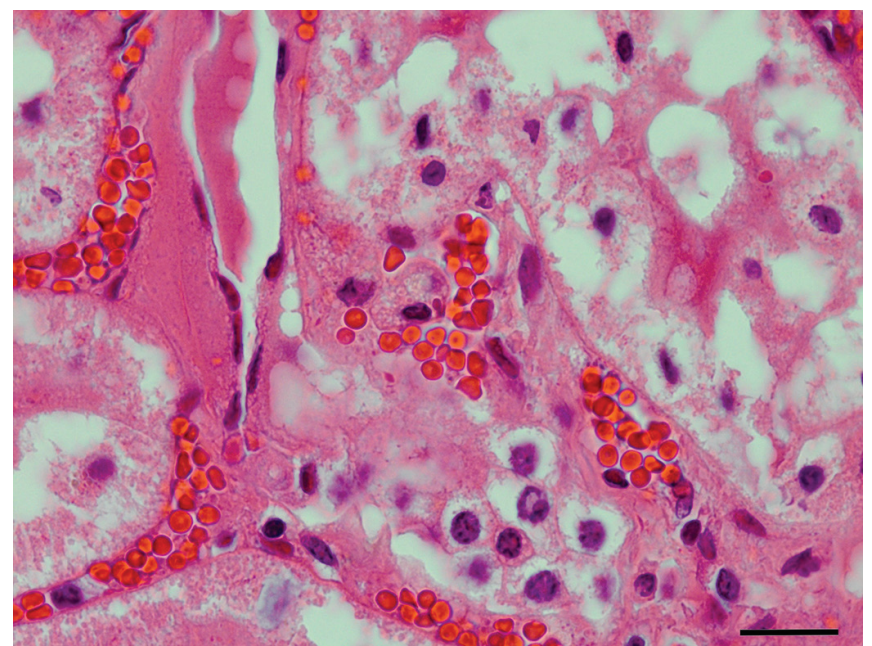

Fig.11. Rim, numerosos eritrócitos nos capilares sanguíneos do interstício (congestão). HE, obj.100x.

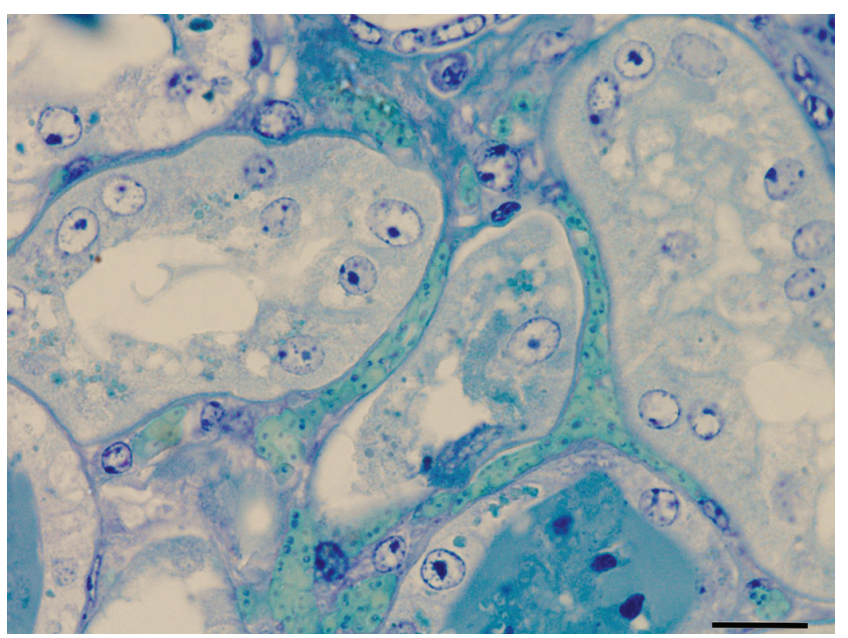

Fig.12. Rim, congestão capilar com numerosos eritrócitos (azul-esverdeados) parasitados por Babesia bovis (azul-escuro). Azul de metileno, obj.100x.

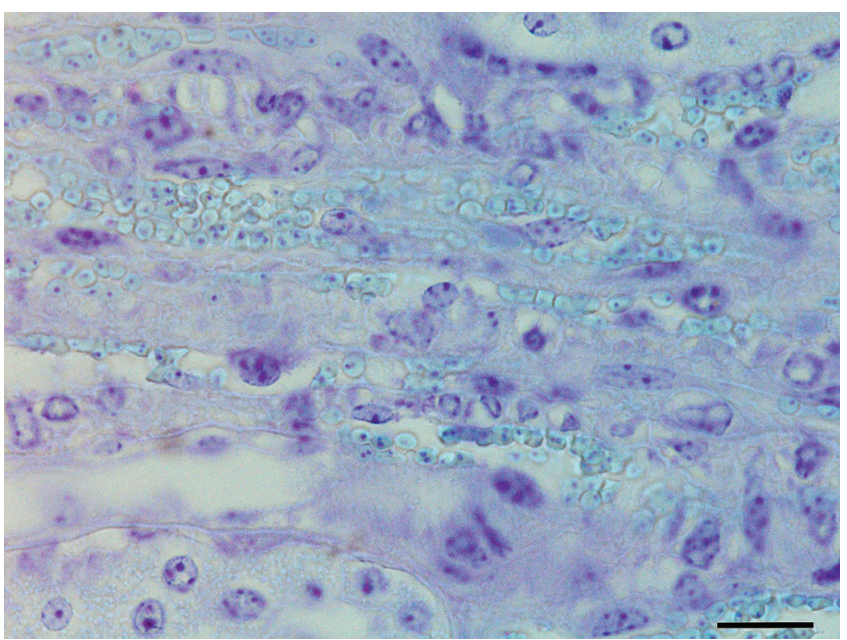

Fig.13. Rim, congestão capilar com numerosos eritrócitos (amarelo-esverdeados) parasitados por Babesia bovis (azul-escuro). Azul de toluidina, obj.100x.

patologista. Somente as alterações clínico-epidemiológicas, lesões macroscópicas, lesões microscópicas e aspectos histoquímicos dos casos positivos para B. bovis serão descritos a seguir.

Alterações clínico-epidemiológicas. Dos 21 bovinos positivos para B. bovis, 20 morreram espontaneamente e em um caso esta informação estava ausente. As fêmeas foram acometidas em 14 casos, machos em 6 e em um caso não havia informação do sexo. A idade dos animais variou de 15 dias a nove anos, porém a maioria dos animais tinha entre um e quatro anos (16/21). Com relação às raças, 15 casos eram de origem europeia, quatro casos não tinham raça definida e em dois não havia tal informação. Quanto à época de ocorrência, sete ocorreram no outono, oito no verão, quatro no inverno e dois na primavera. Dentre os 21 bovinos positivos, em 11 havia sido realizado tratamento para TPB, entretanto em apenas seis foi informado o medicamento utilizado. Os fármacos mais utilizados foram diaceturato de diminazeno, dipropionato de imidocarb e oxitetraciclina.

Os sinais clínicos mais frequentes foram febre $(6 / 21)$, anemia $(5 / 21)$, decúbito $(4 / 21)$, anorexia $(3 / 21)$, diarreia $(3 / 21)$, apatia $(3 / 21)$ e icterícia $(2 / 21)$. Alguns bovinos apresentaram sinais neurológicos que consistiam de agressividade $(3 / 21)$, andar cambaleante $(2 / 21)$, dificuldade de locomoção $(2 / 21)$ e tremores musculares $(1 / 21)$. Outros achados menos frequentes foram hemoglobinúria $(3 / 21)$, prostração, sialorreia e diminuição dos movimentos ruminais $(2 / 21)$, taquicardia $(2 / 21)$, afastamento do rebanho $(2 / 21)$, secreção mucopurulenta na conjuntiva e edema palpebral (1/21), emagrecimento e orelhas caídas (1/21) e dificuldade respiratória (1/21). Em um caso o animal foi encontrado morto sem sinais clínicos prévios.

Lesões macroscópicas. 0 encéfalo foi enviado em quatro casos $(4 / 21)$, nos quais não foram observadas alterações macroscópicas. 0 rim foi enviado em 15 casos, dos quais 10 apresentaram-se vermelho-escuros. 0 fígado somente não foi remetido em um caso e nos demais, o órgão estava alaranjado (7/20), esverdeado (após a fixação) $(4 / 20)$ ou amarelado $(1 / 20)$. Foi ainda informado que o fígado estava aumentado de tamanho em cinco casos. 0 baço foi enviado em 15 casos, nos quais as alterações mais observadas foram protrusão 
da polpa vermelha sobre a cápsula $(8 / 15)$, esplenomegalia (7/15) e parênquima de aspecto carnoso (4/15).

Lesões microscópicas. No encéfalo havia congestão leve dos capilares do córtex encefálico em dois casos (2/4). Nos rins observou-se necrose tubular (8/15), cilindros de hemoglobina $(7 / 15)$, cilindros hialinos $(3 / 15)$, congestão difusa $(2 / 15)$ e regeneração tubular $(1 / 15)$. No fígado, a lesão mais observada foi a bilestase canalicular e ductal $(15 / 20)$, necrose centrolobular $(7 / 20)$ a paracentral $(6 / 20)$, degeneração gordurosa $(7 / 20)$, leucocitostase sinusoidal $(6 / 20)$, eritropoiese extramedular $(5 / 20)$ e eritrofagia $(3 / 20)$. Lesões menos frequentes foram congestão do parênquima $(3 / 20)$, necrose individual de hepatócitos $(2 / 20)$ e raros agregados de neutrófilos nos espaços-porta $(1 / 20)$. Congestão esplênica foi a lesão mais frequentemente observada (13/15), seguida de macrófagos com hemossiderina (3/15), eritrofagocitose (3/15) e eritropoiese extramedular na polpa vermelha $(3 / 15)$.

Aspectos histoquímicos. No Quadro 2 estão detalhados os achados histoquímicos das técnicas de HE, AM e AT aplicadas no grupo B. Semelhantemente ao observado no grupo A, houve melhor evidenciação dos protozoários por meio das colorações de AM e AT comparado à técnica de HE.

Quadro 2. Propriedades histoquímicas da infecção por Babesia bovis nos bovinos do grupo B

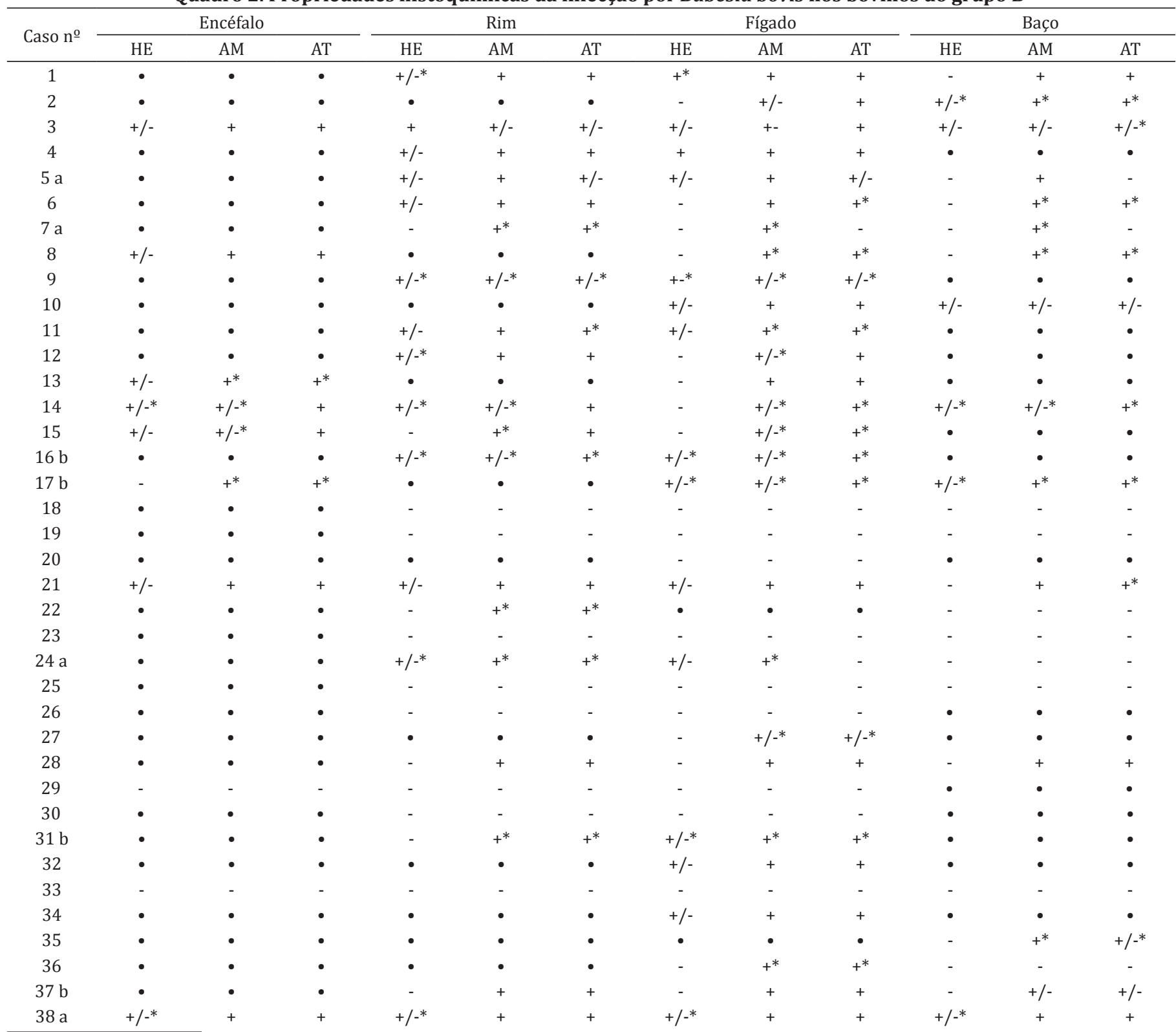

- Não remetido, ${ }^{*}$ casos em que foi necessário o uso da imersão. A presença dos micro-organismos foi classificada em positiva (+ quando os protozoários foram facilmente observados), fraca (+/- quando foram observados protozoários, porém com pouca nitidez) ou negativa (- quando não foram observados protozoários intraeritrocitários); $\mathrm{a}=$ casos de Babesia bigemina, $\mathrm{b}=$ casos de Anaplasma spp., $\mathrm{HE}=$ hematoxilina e eosina, AM = azul de metileno, $\mathrm{AT}=$ azul de toluidina . 


\section{DISCUSSÃO}

Parte deste estudo diz respeito à caracterização dos aspectos clínico-epidemiológicos e anatomopatológicos da babesiose bovina por Babesia bovis. Observou-se que, apesar de não haver predisposição por sexo (Barros et al. 2006), houve predomínio de fêmeas em ambos os grupos. Os animais com idade entre um e três anos foram os mais acometidos no grupo A, e entre um e quatro anos no grupo B, semelhantemente ao que é descrito na literatura (Rodrigues et al. 2005, Almeida et al. 2006). Este fato se deve a primo-infecção dos animais com mais de 10 meses, visto que os bezerros são protegidos por imunidade não específica até aproximadamente 7-11 meses de idade (Farias 2007, Costa et al. 2011). Conforme a literatura, as raças de origem europeia são mais sensíveis à infestação pelo carrapato (Almeida et al. 2006, Farias 2007), e como observado neste estudo, mais suscetíveis à infecção por Babesia spp. (De Vos \& Potgieter 1994, Barros et al. 2006).

Os sinais clínicos observados nos bovinos do grupo A (com lesão encefálica macroscópica patognomônica), foram considerados como os mais característicos desta doença na sua forma neurológica, conforme descrito na literatura (Callow \& McGavin 1963, De Vos \& Potgieter 1994, Rodrigues et al. 2005). Como estes sinais neurológicos são inespecíficos, a babesiose cerebral deve ser diferenciada de outras doenças que acometem o SNC de bovinos como raiva, infecção pelo herpesvírus bovino tipo 1 ou tipo 5 e seneciose com manifestação neurológica (Rodrigues et al. 2005, Almeida et al. 2006, Barros et al. 2006, Farias 2007, Antoniassi et al. 2009). Outros sinais comumente observados estão relacionados com o fato de a babesiose ser um distúrbio hemolítico intravascular e acarretar sinais clínicos e lesões macroscópicas caracterizadas por anemia, hemoglobinúria e icterícia (Fighera 2001, Barros et al. 2006, Fighera \& Graça 2010).

Lesões macroscópicas relacionadas à anemia hemolítica como esplenomegalia, hepatomegalia, fígado alaranjado, rins vermelho-escuros e urina vermelho-escura são alterações muito frequentes nesta doença (Barros et al. 2006, Antoniassi et al. 2009, Fighera \& Graça 2010) e sempre devem remeter à um quadro de babesiose, como foi observado em ambos os grupos deste estudo. A coloração róseo-cereja da substância cinzenta do encéfalo é patognomônica de babesiose cerebral em bovinos, a qual é causada por B. bovis (De Vos \& Potgieter 1994, Rodrigues et al. 2005, Barros et al. 2006, Antoniassi et al. 2009, Fighera \& Graça 2010). Embora essa alteração macroscópica seja característica da infecção por este protozoário em bovinos, uma lesão idêntica tem sido observada também em gatos infectados por B. lengau (Bosman et al. 2013) e em pessoas afetadas por malária falcípara (Samuelson 1999). Esta característica foi utilizada neste estudo, como critério de inclusão para os casos do grupo A, por conferir maior confiabilidade às observações histológicas e histoquímicas referentes ao agente $B$. bovis. Esta alteração ocorre devido à estase dos eritrócitos parasitados nos pequenos capilares encefálicos (Antoniassi et al. 2009, Fighera \& Graça 2010), permitindo identificar os organismos principalmente através de esfregaços do córtex cerebral, mas também em cortes histológicos (Kessler et al. 1983, Rodrigues et al. 2005, Barros et al. 2006, Fighera \& Graça 2010), como observado neste estudo. Em alguns casos do grupo B, em que o encéfalo foi remetido, foram observadas babesias através das colorações histoquímicas, apesar da lesão macroscópica não estar presente.
Isto pode ser explicado pelo fato de alguns materiais terem sido remetidos já fixados em formol, ou enviados congelados (o que mascara a lesão macroscópica) ou ainda porque a congestão dos capilares era leve, sendo insuficiente para desenvolver a lesão macroscópica característica.

A localização do protozoário nos capilares dos órgãos internos é uma característica biológica da espécie B. bovis (Callow \& McGavin 1963, Young \& Morzaria 1986) e os achados histoquímicos deste estudo, corroboram com esta informação, pois o agente era observado principalmente no encéfalo, rim e fígado, em ordem decrescente de frequência. Esta espécie de protozoário induz o acúmulo de eritrócitos parasitados nesses pequenos vasos, causando estase e obstrução dos mesmos através da ativação dos sistemas das cininas, da coagulação e do complemento. Acredita-se que as alterações degenerativas de anóxia façam parte da patogênese no desenvolvimento dos sinais neurológicos da babesiose cerebral (Kessler et al. 1983, Fighera 2001, Rodrigues et al. 2005, Uilenberg 2006). Lesões microscópicas relacionadas a distúrbios hemolíticos (bilestase, acúmulos de hemossiderina, necrose e regeneração de túbulos, formação de cilindros de hemoglobina e necrose hepática centrolobular), como vistas nos bovinos deste estudo, sempre devem levantar a suspeita de babesiose (Rodrigues et al. 2005, Barros et al. 2006, Farias 2007, Fighera \& Graça 2010).

Informações referentes ao tratamento para babesiose são muito importantes no que se refere ao estabelecimento do diagnóstico, pois os medicamentos específicos destroem os protozoários intraeritrocitários em torno de 24 horas após a instituição do mesmo, diminuindo substancialmente a possibilidade de encontrar os agentes durante o diagnóstico citológico e histopatológico (Barros et al. 2006). Apesar disso, observou-se que em ambos os grupos deste estudo, mesmo nos casos em que havia histórico de tratamento prévio, foi possível visualizar os parasitos através das colorações histoquímicas. Para explicar este fato, sugere-se que o tempo de instituição da medicação específica pode ter sido inferior às 24 horas, que a dose foi inferior à recomendada ou ainda que o inóculo de babesias fosse muito grande para que o medicamento pudesse destruí-las.

As maiores dificuldades para confirmar o diagnóstico histopatológico de babesiose cerebral por B. bovis, estão relacionadas ao envio inadequado de material, como amostras congeladas, autolisadas, realização de tratamento prévio, mas, principalmente, material já fixado em formol, pois isto mascara a coloração róseo-cereja do encéfalo e dificulta a suspeita de babesiose, impedindo a realização de esfregaços de órgãos, sobretudo do encéfalo. Adicionalmente, a visualização do agente através da coloração de rotina (HE) é limitada. Apesar de esta técnica ser empregada de forma ampla em histopatologia, nem todas as estruturas contidas nos tecidos podem ser demonstradas nitidamente através dela (Maxie \& Miller 2016).

Na literatura, algumas colorações já foram utilizadas para demonstrar protozoários em esfregaços sanguíneos, como Giemsa (Gardiner et al. 1998), panótico rápido (Rodrigues et al. 2005), azul de metileno para malária (Brasil 2005) e para rickettsias como Anaplasma spp. (Potgieter \& Stoltsz 1994). Informações sobre a utilização de colorações especiais para detecção de protozoários em seções de tecidos são escassas, particularmente no que se refere à $B$. bovis. Para este agente 
e para Cowdria ruminantium já foi descrita a utilização do Giemsa em cortes histológicos (Callow \& McGavin 1963, Prozesky 1987, Nevils et al. 2000). No entanto, algumas outras técnicas histoquímicas são mencionadas genericamente para detecção de protozoários incluindo hematoxilina-férrica, PAS, Gram, Ziehl-Neelsen e Grocott (Gardiner et al. 1998).

Baseado nisso, foram testadas colorações especiais comumente presentes em laboratórios de patologia, numa tentativa de encontrar técnicas capazes de melhor evidenciar B. bovis. As colorações de AM, AT e Giemsa revelaram a presença dos agentes intraeritrocitários. Entretanto, dentre estas técnicas, elegeram-se as colorações de AM e AT para serem empregadas no grupo B, por serem as técnicas mais práticas (menor tempo de execução), por demonstrarem maior nitidez para evidenciação da morfologia de B. bovis, quando comparado com o HE e com o Giemsa, e porque esta última coloração já havia sido descrita anteriormente (Callow \& McGavin 1963, Nevils et al. 2000). A coloração de ZN não apresentou a sua característica de álcool-ácido resistência para B. bovis, porém o organismo foi visualizado por ter sido corado pelo AM, que é o corante da contracoloração desta técnica (Behmer et al. 1976, Prophet et al. 1992). De forma semelhante, quando a técnica do PAS foi empregada, $B$. bovis foi evidenciada somente pela contracoloração com hematoxilina de Carazzi. As técnicas AA, Grocott e Gram não detectaram B. bovis.

Várias reações podem ocorrer entre os corantes e os elementos-alvo nos tecidos. Dentre eles podem ser consideradas as ligações eletrostáticas, de hidrogênio, covalentes e hidrofóbicas, forças de Van der Wall, agregações de corantes e permeabilidade tecidual. Todavia, o mecanismo de afinidade entre o corante e seu alvo é conhecido em relativamente poucas colorações histoquímicas. Isso pode ser considerado como de menor importância quando a coloração é empregada especificamente para melhorar a evidenciação das características morfológicas de um agente, como nesse estudo (Culling et al. 1985). Dessa forma, as interações específicas entre os corantes de AM e AT e os micro-organismos aqui estudados não puderam ser determinadas.

As técnicas de AM e AT facilitaram a visualização e determinação da espécie dos agentes da TPB, dando ênfase para B. bovis, pois evidenciaram os organismos por meio de seu contraste com o eritrócito. A técnica do AM apresentou maior nitidez na detecção e identificação da morfologia de B. bovis em relação ao AT, corando os eritrócitos de azul-claro esverdeado, enquanto que os parasitos coraram-se de azul-escuro e tinham seus limites bem definidos. Ambas as técnicas permitiram comparar o tamanho do agente com o tamanho do eritrócito o que facilitou a determinação de sua espécie. Observou-se que $B$. bovis foi a espécie com maior número de organismos nas lesões, e diferenciou-se de B. bigemina por esta ser bem maior e ocupar aproximadamente a metade do tamanho de um eritrócito. Enquanto que $A$. marginale era dificilmente observado, sendo possível somente com o uso da imersão (1000x). Quanto à localização dos organismos observou-se que $B$. bovis, pela sua característica biológica já descrita (Callow \& McGavin 1963, Young \& Morzaria 1986), localizou-se principalmente em capilares do encéfalo, como visto no grupo A, seguido do rim, fígado e baço. Já B. bigemina foi observado em menor número, porém em vasos de diferentes calibres. Quanto a A. marginale, este era de difícil visualização sem o auxílio de imersão e o órgão onde melhor se observou o organismo foi o baço. Esta observação está possivelmente relacionada à sua característica de desenvolver hemólise extravascular.

O AM não é frequentemente utilizado como uma coloração primária na rotina histoquímica da maioria dos laboratórios. Esta técnica é utilizada em esfregaços sanguíneos para a pesquisa de Plasmodium spp., causador da malária (Prophet et al. 1992), e Anaplasma spp. utilizando luz ultravioleta (Potgieter \& Stoltsz 1994). Ela também já foi descrita para detectar bactérias em geral e substância de Nissl (Behmer et al. 1976), e para detecção de fibras e terminações nervosas (Culling et al. 1985).

O corante AT é utilizado rotineiramente para corar metacromaticamente (de um vermelho-arroxeado) os grânulos dos mastócitos (Prophet et al. 1992, Behmer et al. 1976). Entretanto, para os agentes aqui estudados, o uso do corante AT revelou um efeito ortocromático (onde os elementos-alvo coram-se em azul) (Culling et al. 1985). Além disso, o AT também é descrito como utilizado para detectar fungos (Culling et al. 1985), para avaliar a qualidade da matriz cartilaginosa em seções descalcificadas e para demonstrar matriz osteoide mineralizada em seções não descalcificadas, mucina (Maxie \& Miller 2016), amiloide sob luz polarizada, sedimento de líquido cefalorraquidiano, células cromafins (Behmer et al. 1976) e substância de Nissl (Culling et al. 1985, Behmer et al. 1976). O AT já foi utilizado em esfregaços sanguíneos sob luz ultravioleta para detectar Anaplasma spp. (Potgieter \& Stoltsz 1994).

\section{CONCLUSÕES}

O principal objetivo deste estudo foi alcançado ao encontrarem-se duas colorações histoquímicas (de fácil utilização), Azul de Metileno e Azul de Toluidina, que permitiram a evidenciação nítida dos organismos intraeritrocitários e se mostraram mais eficazes que a técnica de HE.

Estas técnicas permitiram observar características morfológicas auxiliares no diagnóstico de babesiose bovina por Babesia bovis, mas também permitiram o diagnóstico diferencial de babesiose por Babesia bigemina e anaplasmose por Anaplasma marginale.

Adicionalmente, analisaram-se vários parâmetros clínico-epidemiológicos e anatomopatológicos importantes no diagnóstico de babesiose causada por B. bovis.

Agradecimentos.- T.M. Silva (Mestrado) foi bolsista CNPq. G.D. Kommers é bolsista de Produtividade do CNPq.

\section{REFERÊNCIAS}

Almeida M.B., Tortelli F.P., Riet-Correa B., Ferreira J.L.M., Soares M.P., Farias N.A.R., Riet-Correa F. \& Schild A.L. 2006. Tristeza parasitária bovina na região sul do Rio Grande do Sul: estudo retrospectivo de 1978-2005. Pesq. Vet. Bras. 26(4):237-242. http://dx.doi.org/10.1590/S0100-736X2006000400008.

Antoniassi N.A.B., Corrêa A.M.R., Santos A.S., Pavarini S.P., Sonne L., Bandarra P.M. \& Driemeier D. 2009. Surto de babesiose cerebral em bovinos no Estado do Rio Grande do Sul. Ciência Rural 39(3):933-936. http://dx.doi. org/10.1590/S0103-84782009000300049.

Barros C.S.L., Driemeier D., Dutra I.S. \& Lemos R.A.A. 2006. Doenças do Sistema Nervoso de Bovinos no Brasil. Vallée, Montes Claros, p.87-95.

Behmer O.A., Tolosa E.M.C. \& Freitas Neto A.G. 1976. Manual de Técnicas para Histologia Normal e Patológica. Edart, São Paulo, p.88-167. 
Bosman A.M., Oosthuizen M.C., Venter E.H., Steyl J.C., Gous T.A. \& Penzhorn B.L. 2013. Babesia lengau associated with cerebral and haemolytic babesiosis in two domestic cats. Parasit. Vectors 6(1):128. http://dx.doi. org/10.1186/1756-3305-6-128. PMid:23634743.

Brasil 2005. Manual de Diagnóstico Laboratorial da Malária. Secretaria de Vigilância em Saúde, Ministério da Saúde. Brasília, p.19.

Callow L.L. \& McGavin M.D. 1963. Cerebral babesiosis due to Babesia argentina. Aust. Vet. J. 39(1):15-21. http://dx.doi.org/10.1111/j.1751-0813.1963. tb04170.x.

Costa V.M., Rodrigues A.L., Medeiros J.M.A., Labruna M.B., Simões S.V.D. \& Riet-Correa F. 2011. Tristeza parasitária bovina no Sertão da Paraíba. Pesq. Vet. Bras. 31(3):239-243. http://dx.doi.org/10.1590/S0100736X2011000300009.

Culling C.F.A., Allison R.T. \& Barr W.T. 1985. Celular Pathology Technique. 4th ed. Butterworths, London. p.116-453.

De Vos A.J. \& Potgieter F.T. 1994. Bovine babesioses, p.278-294. In: Coetzer J.A.W., Thomson G.R. \& Tustin R.C. (Eds), Infectious Disease of Livestock with Special Reference to Southern Africa. Vol.1. Oxford University Press, Cape Town.

Farias N.A. 2007. Tristeza parasitária bovina, p.524-532. In: Riet-Correa F., Schild A.L., Lemos R.A.A. \& Borges J.R.J. (Eds), Doenças de Ruminantes e Equídeos. Vol.1. 3a ed. Pallotti, Santa Maria.

Fighera R.A. \& Graça D.L. 2010. Sistema hematopoiético, p.311-406. In: Santos R.L. \& Alessi A.C. (Eds), Patologia Veterinária. Roca, São Paulo.

Fighera R.A. 2001. Anemia em Medicina Veterinária. Pallotti, Santa Maria, p.65-71.

Gardiner C.H., Fayer R. \& Dubey J.P. 1998. An Atlas of Protozoan Parasites in Animal Tissue. 2nd ed. Armed Forces Institute of Pathology, Washington, p.71-72

Kessler R.H., Madruga C.R., Schenk M.A.M. \& Ribeiro O.C. 1983. Babesiose cerebral por Babesia bovis (Babés 1888 Starcovici 1893) em bezerros, no estado de Mato Grosso do Sul. Pesq. Agropec. Bras. 18(8):931-933.

Maxie M.G. \& Miller M.A. 2016. Introduction to the diagnostic process. In: Maxie M.G. (Ed.), Jubb, Kennedy and Palmer's Pathology of Domestic Animals. Vol.1. 6th ed. Elsevier, Missouri. http://dx.doi.org/10.1016/ B978-0-7020-5317-7.00001-1.

Néo T.A., Giglioti R., Obregón D., Bilhassi T.B., Oliveira H.N., Machado R.Z., Aníbal F.F., Brito L.G., Malagó Junior W., Bressani F.A. \& Oliveira M.C.S.
2016. Detection of Babesia bovis and Babesia bigemina in water buffaloes (Bubalus bubalis) in endemic areas of São Paulo state, Brazil. Open J. Vet. Med. 6(5):75-84. http://dx.doi.org/10.4236/ojvm.2016.65009.

Nevils M.A., Figueroa J.V., Turk J.R., Canto G.J., Le V., Ellersieck M.R. \& Carson C.A. 2000. Cloned lines of Babesia bovis differ in their ability to induce cerebral babesiosis in cattle. Parasitol. Res. 86(6):437-443. http://dx.doi. org/10.1007/s004360050691. PMid:10894468.

OIE 2010. Bovine Babesiosis. Chapter 2.4.2. Paris, p. 611-623. Disponível em <http://www.oie.int/fileadmin/Home/eng/Health_standards/tahm/2008/ pdf/2.04.02_BOVINE_BABESIOSIS.pdf> Acesso em 24 mai. 2015.

Patarroyo J.H., Vargas M.I. \& Bicudo P.L. 1982. Description of lesions in cattle in a natural outbreak of Babesia bovis infection in Brazil. Vet. Parasitol. 11(4):301-308. http://dx.doi.org/10.1016/0304-4017(82)90098-X. PMid:6892174.

Potgieter F.T. \& Stoltsz W.H. 1994. Bovine anaplasmosis, p.407-430. In: Coetzer J.A.W., Thomson G.R. \& Tustin R.C. (Eds), Infectious Disease of Livestock With Special Reference to Southern Africa. Vol.1. Oxford University Press, Cape Town.

Prophet E.B., Mills B., Arrington J.B. \& Sobin L.H. 1992. AFIP Laboratory Methods in Histotechnology. American Registry of Pathology, Washington. p.216-219

Prozesky L. 1987. Heartwater: the morphology of Cowdria ruminantium and its staining characteristics in the vertebrate host and in vitro. Onderstepoort J. Vet. Res. 54(3):173-176. PMid:2452396.

Rodrigues A., Rech R.R., Barros R.R., Fighera R.A. \& Barros C.S.L. 2005. Babesiose cerebral em bovinos: 20 casos. Ciência Rural 35(1):121-125. http://dx.doi.org/10.1590/S0103-84782005000100019.

Samuelson J. 1999. Infectious diseases, p.389-391. In: Cotran R.S., Kumar V. \& Collins T. (Eds), Robbins Pathologic Basis of Disease. 6th ed. W.B. Saunders, Philadelphia.

Sanches A.W.D., Langohr I.M., Stigger A.L. \& Barros C.S.L. 2000. Doenças do sistema nervoso central em bovinos no Sul do Brasil. Pesq. Vet. Bras. 20(3):113-118. http://dx.doi.org/10.1590/S0100-736X2000000300005.

Uilenberg G. 2006. Babesia: a historical overview. Vet. Parasitol. 138(1/2):310. http://dx.doi.org/10.1016/j.vetpar.2006.01.035. PMid:16513280.

Young A.S. \& Morzaria S.P. 1986. Biology of Babesia. Parasitol. Today 2(8):211219. http://dx.doi.org/10.1016/0169-4758(86)90084-0. PMid:15462841. 